Article

\title{
Evaluation of Accuracy and Practical Applicability of Methods for Measuring Leaf Reflectance and Transmittance Spectra
}

\author{
Aarne Hovi ${ }^{1, *}$, Petri Forsström ${ }^{1,2}$, Matti Mõttus ${ }^{3}$ (D) and Miina Rautiainen ${ }^{1,2}$ \\ 1 Department of Built Environment, School of Engineering, Aalto University, P.O. Box 14100, \\ FI-00076 Aalto, Finland; petri.forsstrom@aalto.fi (P.F.); miina.a.rautiainen@aalto.fi (M.R.) \\ 2 Department of Electronics and Nanoengineering, School of Electrical Engineering, Aalto University, \\ P.O. Box 15500, FI-00076 Aalto, Finland \\ 3 VTT Technical Research Centre of Finland, P.O. Box 1000, FI-02044 VTT Espoo, Finland; \\ matti.mottus@gmail.com \\ * Correspondence: aarne.hovi@aalto.fi; Tel.: +358-50-406-4147
}

Received: 6 October 2017; Accepted: 21 December 2017; Published: 24 December 2017

\begin{abstract}
Leaf reflectance and transmittance spectra are urgently needed in interpretation of remote sensing data and modeling energy budgets of vegetation. The measurement methods should be fast to operate and preferably portable to enable quick collection of spectral databases and in situ measurements. At the same time, the collected spectra must be comparable across measurement campaigns. We compared three different methods for acquiring leaf reflectance and transmittance spectra. These were a single integrating sphere (ASD RTS-3ZC), a small double integrating sphere (Ocean Optics SpectroClip-TR), and a leaf clip (PP Systems UNI501 Mini Leaf Clip). With all methods, an ASD FieldSpec 4 spectrometer was used to measure white paper and tree leaves. Single and double integrating spheres showed comparable within-method variability in the measurements. Variability with leaf clip was slightly higher. The systematic difference in mean reflectance spectra between single and double integrating spheres was only minor (average relative difference of $1 \%$ ), whereas a large difference $(14 \%)$ was observed in transmittance. Reflectance measured with leaf clip was on average $14 \%$ higher compared to single integrating sphere. The differences between methods influenced also spectral vegetation indices calculated from the spectra, particularly those that were designed to track small changes in spectra. Measurements with double integrating sphere were four, and with leaf clip six times as fast as with single integrating sphere, if slightly reduced signal level (integration time reduced from optimum) was allowed for the double integrating sphere. Thus, these methods are fast alternatives to a conventional single integrating sphere. However, because the differences between methods depended on the measured target and wavelength, care must be taken when comparing the leaf spectra acquired with different methods.
\end{abstract}

Keywords: spectroscopy; integrating sphere; leaf clip; contact probe; leaf optical properties; reflectance; transmittance; albedo

\section{Introduction}

Information on leaf optical properties is utilized, for example, in interpretation of data from remote sensing instruments, as well as in modeling energy budgets of vegetation canopies. Therefore, there is an urgent need for spectral libraries that would contain information on species-specific leaf reflectance and transmittance spectra and their response to various environmental factors. When collecting spectral libraries, it is essential that the collected data are comparable across measurement campaigns. Another important requirement is that the applied measurement methods should be easy 
to operate so that a sufficiently large number of observations can be collected with limited resources. The ability to perform measurements fast is important also because the physiological status of plants may change rapidly in time, both in laboratory and field measurements.

Measurements of leaf reflectance and transmittance spectra are traditionally obtained with integrating spheres [1-5]. The commercial integrating spheres usually employ a directionalhemispherical measurement geometry, in which the incidence angle of the incoming collimated light beam is close to surface normal, and reflected or transmitted light are collected over the entire hemisphere [6]. Integrating spheres are relatively large and heavy, and not very easy to transport into remote locations for field measurements. Portable systems such as contact probes [7-10], however, can be applied to measure spectra in situ so that storage of the leaf samples can be avoided. Contact probes illuminate the leaf very close to its surface and make measurements in a bi-directional (hotspot) view-illumination geometry. The biggest disadvantage is that only the reflectance spectrum can be measured, although an estimate of transmittance can be obtained by measuring the target sequentially with dark and bright backgrounds [11]. Recently, a new double integrating sphere (SpectroClip-TR) was introduced by Ocean Optics [12]. Although the idea of double integrating sphere is not new [13,14], this system is particularly promising since it employs measurement geometry similar to traditional integrating spheres, yet it is lightweight and small. Thus, SpectroClip-TR is potentially suitable for measurements in remote locations or for non-destructive in situ measurements. In addition, reflectance and transmittance measurements are performed simultaneously from the same spot on the leaf, which reduces uncertainty in the measurements. Because the system is new, its accuracy against more conventional methods has not yet been thoroughly evaluated in leaf measurements. Only a validation of reflectance measurements with the instrument has been reported recently [15].

Although leaf optical properties have been measured for a long time, very little is known about the comparability of various measurement methods. One of the few previous intercomparison studies assessed four integrating spheres applicable in laboratory conditions [16]. Generally, the measured reflectance and transmittance spectra were consistent between the tested spheres. However, it is expected that the differences are larger if methods which are more different, e.g., in terms of measurement geometry, are compared. For example, there is evidence that a contact probe and an integrating sphere produce different reflectance values $[17,18]$.

We performed a comparison of three fundamentally different measurement methods for obtaining leaf reflectance and transmittance spectra: A single integrating sphere (ASD RTS-3ZC), a double integrating sphere (Ocean Optics SpectroClip-TR), and a leaf clip that employs a contact-probe type of measurement geometry (PP Systems UNI501 Mini Leaf Clip). Differences between methods are expected, because the methods differ by their measurement geometry, portability, and partly also by main application (measurements of living plants in the field vs. measurement of detached leaves in laboratory). Quantitative information on the differences is needed when evaluating which of the methods is best suitable for certain application. The specific research questions that we addressed were:

- How much within-method variability do the measurements have, i.e., how many measurements are needed to obtain reliably the mean spectra of a given target?

- Are there systematic differences in mean spectra of the same targets measured with different methods?

In addition, we evaluated the measurement speed and discussed other practical issues related to portability and ease of operation. The results help potential users in selecting best methods for their applications, and illustrate expected differences when spectra acquired with different methods are compared or combined, for example in collection of vegetation spectral libraries. 


\section{Materials and Methods}

\subsection{Overview of the Experiment}

In this study, we used three methods: A single integrating sphere (SIS), double integrating sphere (DIS), and leaf clip (LC). To normalize measurement conditions, we operated all methods in a laboratory, together with and ASD FieldSpec 4 Standard-Res spectrometer which measures at wavelengths of 350-2500 nm. To quantify within-method variability and systematic differences between methods, we measured reflectance and transmittance of leaves of Norway maple (Acer platanoides L.) and silver birch (Betula pendula Roth) trees, and Whatman 114 white laboratory filter paper (Table 1). Additionally, reflectance measurements of SIS and DIS were evaluated in absolute terms by measuring calibrated gray-level standards (5\%,20\%, and 50\% nominal reflectances) by Avian Technologies. The reflectance standards were not measured with LC, because due to its design (sharp edges) LC easily damaged the surface of the standards. Transmittance was only evaluated in relative terms. Due to transmission properties of the fiber optic cables used, the comparisons of the methods were performed at 400-2100 nm (DIS vs. SIS) and 400-1500 nm (LC vs. other methods). Speed of operation was evaluated by recording the time needed for measurement of one leaf when measuring the birch leaves. In the following, we first describe the three measurement methods in detail (Section 2.2), followed by descriptions of our measurements (Section 2.3). Data analyses are described in Section 2.4.

Table 1. Measured samples and quantities $(R=$ reflectance, $T=$ transmittance $)$ with each method.

\begin{tabular}{ccccc}
\hline & $\begin{array}{c}\text { Single Integrating } \\
\text { Sphere (SIS) }\end{array}$ & $\begin{array}{c}\text { Double Integrating } \\
\text { Sphere (DIS) }\end{array}$ & $\begin{array}{c}\text { Leaf Clip } \\
\text { (LC) }\end{array}$ & $\begin{array}{c}\text { Number of Measurements } \\
\text { per Method }\end{array}$ \\
\hline Birch leaves & $\mathrm{R} / \mathrm{T}$ & $\mathrm{R} / \mathrm{T}$ & $\mathrm{R}$ & $18^{*}$ \\
Maple leaves & $\mathrm{R} / \mathrm{T}$ & $\mathrm{R} / \mathrm{T}$ & $\mathrm{R}$ & $18^{*}$ \\
White paper & $\mathrm{R} / \mathrm{T}$ & $\mathrm{R} / \mathrm{T}$ & $\mathrm{R}$ & 6 \\
Gray-level standard, 5\% & $\mathrm{R}$ & $\mathrm{R}$ & - & 6 \\
Gray-level standard, 20\% & $\mathrm{R}$ & $\mathrm{R}$ & - & 6 \\
Gray-level standard, 50\% & $\mathrm{R}$ & $\mathrm{R}$ & - & 6 \\
\hline
\end{tabular}

* Separate 18 leaves were measured with each method, one measurement per leaf. Both adaxial (upper) and abaxial (lower) sides of the leaves were measured.

\subsection{Measurement Methods}

\subsubsection{ASD RTS-3ZC Single Integrating Sphere (SIS)}

ASD RTS-3ZC is one of the most commonly used integrating spheres in leaf optical properties measurements. It is relatively small-sized (internal diameter of $76 \mathrm{~mm}$ ), and suitable for field measurements, at least if very fast operation and portability are not important. The sample is illuminated with a direct beam, using a $10 \mathrm{~W}$ collimated ASD CL-10 halogen light source, and the radiant power inside the sphere is collected with a fiber optic cable from the spectrometer attached to the top of the sphere. Following the manufacturer's recommendation, we performed measurements in the comparison mode, in order to avoid substitution errors [19]. Reflectance $(R)$ and transmittance $(T)$ of the sample were obtained as:

$$
\begin{gathered}
R=\frac{I_{s, R}-I_{s t r, R}}{I_{r e f, R}-I_{s t r, R}} \times R_{r e f}, \\
T=\frac{I_{s, T}}{I_{r e f, T}-I_{s t r, T} \times\left(1-R_{r e f}\right)} \times R_{r e f},
\end{gathered}
$$

where $I_{s}, I_{r e f}$, and $I_{s t r}$ are the spectrometer readings obtained from the sample, white reference, and stray light, respectively. Subscripts $R$ and $T$ refer to reflectance and transmittance measurements. $R_{\text {ref }}$ is the reflectance factor of the white reference. Our formula for $T$ (Equation (2)) is slightly different from that given in the RTS-3ZC user manual [19]. We derived Equation (2) for sake of thoroughness (see Appendix A), because different formulas for transmittance in single integrating sphere are reported 
in literature [20-22], often without theoretical justifications. The difference between Equation (2) and version reported in RTS-3ZC user manual is however small, provided that the proportion of stray light is small and that the reflectance factor of the white reference is close to unity. The incidence angle of illumination is $13^{\circ}$ in the reflectance measurement, and $0^{\circ}$ in the transmittance measurement. The diameters of all sample ports are $15 \mathrm{~mm}$. In our sphere the diameter of the light beam on the sample was $6.6 \mathrm{~mm}$ in the reflectance measurement, and $7.9 \mathrm{~mm}$ in the transmittance measurement.

\subsubsection{Ocean Optics SpectroClip-TR Double Integrating Sphere (DIS)}

Ocean Optics SpectroClip-TR consists of two small integrating spheres, $20 \mathrm{~mm}$ in diameter. During the measurements, the sample is placed in the sample port between the spheres, and illuminated with a direct beam of light entering through one of the spheres at $8^{\circ}$ angle from surface normal. The light originates from a $20 \mathrm{~W}$ collimated halogen light source (Ocean Optics HL-2000-HP-FHSA) from which it is directed to the sphere through a fiber optic cable and a collimating lens. Each of the spheres has a detector (head of fiber optic cable) that collects the radiant power inside the sphere. These two fiber optic cables were connected to an electronic shutter, which was further connected to the spectrometer. Because the spectrometer had only one fiber optic cable, the connection of the spectrometer was manually switched between the two fiber optic cables originating from the reflectance and transmittance spheres. The effect of manual switching was less than $1 \%$ throughout all wavelengths, i.e., when the fiber optic cable originating from the spectrometer was detached from and re-attached to the port of the switch several times (other parts of the system untouched) the relative variation (range) in the recorded spectra was less than 1\%. The measurement setup has been described in detail by Mõttus et al. [15] who also presented a theoretical algorithm for computing reflectance and transmittance from sample and reference readings. The diameter of the sample port is $6 \mathrm{~mm}$. The diameter of the collimated light beam on the sample was $3.5 \mathrm{~mm}$, but the measured reflectance and transmittance factors are also affected by the diffusely incident flux from sphere walls [15]. All fiber optic cables in the system were of Ocean Optics VIS-NIR low OH content type.

\subsubsection{PP Systems UNI501 Mini Leaf Clip (LC)}

PP Systems UNI501 Mini Leaf Clip represents a contact probe type of measurement which has no integrating sphere to collect the hemispherically scattered radiation from the sample. Instead, bi-directional view-illumination geometry is employed, so that illumination and view angles are the same (i.e., the sample is measured in exact hotspot direction). Because of the small sample port, Mini Leaf Clip is suitable for measuring also coniferous needles or very narrow leaves. However, only reflectance can be measured. During the measurements, the sample is held between two plates made of black Delrin ${ }^{\circledR}$ acetal. The upper plate has a small opening, through which the light from a bifurcated fiber optic cable (PP Systems UNI410) enters the sample. The other leg of the bifurcated cable is then used for transporting the signal reflected from the sample to the spectrometer. The system was described in detail in [10]. The only differences to our study are that we used the Ocean Optics HL-2000-HP-FHSA $20 \mathrm{~W}$ halogen light source and a different spectrometer.

Reflectance of the sample was calculated by comparing the spectrometer readings obtained from the sample and white reference as follows (notation is the same as in Equations (1) and (2)):

$$
R=\frac{I_{s, R}}{I_{r e f, R}} \times R_{r e f}
$$

The light hits the sample with a $30^{\circ}$ incidence angle from surface normal and the average distance between the end of the $0.86 \mathrm{~mm}$-thick fiber optic cable and the sample is $1.8 \mathrm{~mm}$. According to our measurements, an empty clip produces approximately $4 \%$ reflectance signal throughout all wavelengths. Less than half of this originates from areas outside the sample port (open clip in a darkened room produces $<2 \%$ reflectance signal) and the rest from the background. These minor sources of error were not corrected for in Equation (3). 


\subsection{Measurements}

\subsubsection{Measurement Protocols}

The measurements consisted of reflectance, transmittance, and reference readings recorded by the spectrometer. The type and number of reference readings depended on measurement method (Table 2). Uncalibrated Spectralon ${ }^{\circledR}$ panels (99\% nominal reflectance) of 1 -inch diameter were used as white reference. Their reflectance factors were determined through comparison to a calibrated Spectralon. A dark current measurement was taken manually for all three samples by covering the end of the optical fiber of the Spectrometer with a black rubber cap or turning off the switch (in case of DIS and LC). The dark current was subtracted from all spectrometer readings before applying them in calculation of reflectance and transmittance spectra (Section 2.2). The protocols of artificial samples were slightly different: for paper, only one side was measured, and for the gray-level standards, only reflectance was measured.

Table 2. Spectrometer readings needed for calculating reflectance and transmittance of adaxial and abaxial sides of three leaves. Note, that we performed one set of reference readings per three measured samples.

\begin{tabular}{|c|c|c|}
\hline SIS & DIS & LC \\
\hline \multicolumn{3}{|c|}{ Leaf \#1 } \\
\hline White reference for reflectance & White reference & White reference \\
\hline Reflectance (adaxial side) & $\begin{array}{l}\text { Reference reading, empty } \\
\text { reflectance sphere }\end{array}$ & Reflectance (adaxial side) \\
\hline Reflectance (abaxial side) & $\begin{array}{l}\text { Reference reading, empty } \\
\text { transmittance sphere }\end{array}$ & Reflectance (abaxial side) \\
\hline Stray light for reflectance & Transmittance (adaxial side) & \\
\hline White reference for transmittance & Reflectance (adaxial side) & \\
\hline Transmittance (adaxial side) & Reflectance (abaxial side) & \\
\hline Transmittance (abaxial side) & Transmittance (abaxial side) & \\
\hline \multicolumn{3}{|l|}{ Stray light for transmittance } \\
\hline \multicolumn{3}{|c|}{ Leaf \#2 } \\
\hline Transmittance (adaxial side) & Transmittance (adaxial side) & Reflectance (adaxial side) \\
\hline Transmittance (abaxial side) & Reflectance (adaxial side) & Reflectance (abaxial side) \\
\hline Reflectance (adaxial side) & Reflectance (abaxial side) & \\
\hline Reflectance (abaxial side) & Transmittance (abaxial side) & \\
\hline \multicolumn{3}{|c|}{ Leaf \#3 } \\
\hline Reflectance (adaxial side) & Transmittance (adaxial side) & Reflectance (adaxial side) \\
\hline Reflectance (abaxial side) & Reflectance (adaxial side) & Reflectance (abaxial side) \\
\hline Transmittance (adaxial side) & Reflectance (abaxial side) & \\
\hline Transmittance (abaxial side) & Transmittance (abaxial side) & \\
\hline Dark current & Dark current & Dark current \\
\hline
\end{tabular}

\subsubsection{Collection and Measurements of Tree Leaves}

We took samples from a maple and a birch tree (heights $15.6 \mathrm{~m}$ and $18.0 \mathrm{~m}$, respectively) located in the close surroundings of Otaniemi Campus of Aalto University $\left(60^{\circ} 11^{\prime} 14^{\prime \prime} \mathrm{N}, 24^{\circ} 49^{\prime} 36^{\prime \prime} \mathrm{E}\right)$. Measurements for one species were performed within a 3-4 days period (19-22 June for maple, 3-5 June for birch) so that sample branches from selected trees were always collected in the morning (8:40-9:10 a.m. local time), stored in a refrigerator (temperature 3.9-7.5 ${ }^{\circ} \mathrm{C}$ ), and measurements of leaves were performed within $6 \mathrm{~h}$ from the collection of the branch. Branches (length approx. 40-70 cm) were detached from the sunlit (south-facing) side of the tree crown, from approximately $8 \mathrm{~m}$ height. The stem of the branch was cut under water to ensure that the cut surface was fresh, and kept under water while the branch was stored in the refrigerator. Leaves were detached from the branches and 
taken out from the refrigerator immediately before measurement, and measurements were performed according to the protocol in Table 1 . We took one measurement of both adaxial and abaxial sides per each leaf, and measured a total of $18(=6 \times 3)$ leaves per species with each measurement method. The measurement sequence was such that 18 leaves were measured with method \#1, then another 18 leaves with method \#2, and finally another 18 leaves with method \#3. We assumed that leaves collected from the same position of the tree crown have on average similar optical properties, and that the optical properties do not change considerably within the 3-4 days measurement period. This setup is a compromise in order to obtain an adequate number of samples while minimizing the storage times and the overall length of the measurement period, and to avoid mechanical damage of the leaves which could have occurred if the same individual leaves were measured with all methods.

\subsubsection{Spectrometer Settings in the Measurements}

It was important to keep the signal level constant to ensure that varying signal level did not affect the method comparison. To address this issue, we used automatic optimization in FieldSpec 4, which adjusts the integration time for prevailing light conditions. Optimization was always performed while measuring a 99\% Spectralon. The optimal integration times were $0.544 \mathrm{~s}$ for SIS, $8.7 \mathrm{~s}$ for DIS, and $0.136 \mathrm{~s}$ for LC. The differences were due to different light sources and varying amounts of losses in the fiber optics and other parts of the systems. DIS in particular had large attenuation of incident light and detected signal, and therefore required long integration time. To obtain a more realistic estimate of attainable measurement speed if sub-optimal signal level is accepted, we repeated the measurements of birch leaves with DIS, using a shorter $0.544 \mathrm{~s}$ integration time. We always took 15 measurements which were averaged into one spectrometer reading (Table 2), and saved for further processing. Thus, the total time needed for collecting one spectrometer reading was 15 integration times.

\subsection{Analyses of the Measured Spectra}

Within-method variabilities in the measurements were statistically compared using Levene's test for equality of variances. Systematic differences in mean spectra acquired with different methods were evaluated with Welch's $t$-test. Statistical tests were performed in $\mathrm{R}$ statistical software version 3.3.3 [23]. To further examine the influence of between-method differences on the interpretation of the data, we calculated five spectral indices from the measured spectra of birch and maple leaves (Table 3). The indices were chosen so that they covered a wide range of wavelengths. Before calculating the indices, all spectra were smoothed with Savitzky-Golay filter, using second order polynomial and window sizes of $15 \mathrm{~nm}$ (wavelengths below $1000 \mathrm{~nm}$ ) and $39 \mathrm{~nm}$ (wavelengths above $1000 \mathrm{~nm}$ ). Between-method differences in the indices were evaluated statistically using Welch's $t$-test.

Table 3. Spectral indices calculated from the measured reflectance and transmittance spectra. $\mathrm{R}_{\# \#}$ denote the wavelengths used in the calculation.

\begin{tabular}{lccl}
\hline \multicolumn{1}{c}{ Spectral Index } & Abbreviation & Equation & Reference \\
\hline Normalized difference vegetation index & NDVI & $\left(R_{865}-R_{655}\right) /\left(R_{655}+R_{865}\right) *$ & Rouse et al., 1973 [24] \\
Chlorophyll index & CI & $\left(R_{750-800}\right) /\left(R_{520-585}\right)-1$ & Gitelson et al., 2003 [25] \\
Structure insensitive pigment index & SIPI & $\left(R_{800}-R_{445}\right) /\left(R_{800}-R_{680}\right)$ & Peñuelas et al., 1995b [26] \\
Normalized difference water index & NDWI & $\left(R_{860}-R_{1240}\right) /\left(R_{860}+R_{1240}\right)$ & Gao 1996 [27] \\
Normalized difference nitrogen index & NDNI & {$\left[\log \left(1 / R_{1510}\right)-\log \left(1 / R_{1680}\right)\right] /$} & Serrano et al., 2002 [28] \\
& & {$\left[\log \left(1 / R_{1510}\right)+\log \left(1 / R_{1680}\right)\right]$} & \\
\hline
\end{tabular}

* Differing from the original publication, we used central wavelengths of Landsat 8 OLI red and near infrared bands [29]. 


\section{Results}

\subsection{Characteristics of the Measured Spectra}

White paper showed relatively constant reflectance and transmittance (Figure 1). Typical vegetation spectra (absorption peaks in the red and blue regions, sharp red edge, water absorption peaks in the shortwave infrared) were observed for leaves (Figure 1). Reflectance of abaxial leaf side was higher than that of the adaxial side in the visible (VIS, 400-700 nm), and lower in the near-infrared (NIR, 700-1300 $\mathrm{nm}$ ) region. Transmittance of abaxial side was higher compared to adaxial side in NIR and shortwave infrared (SWIR, 1300-2500 nm) regions. The following Sections 3.2-3.4 report the differences between methods in detail.
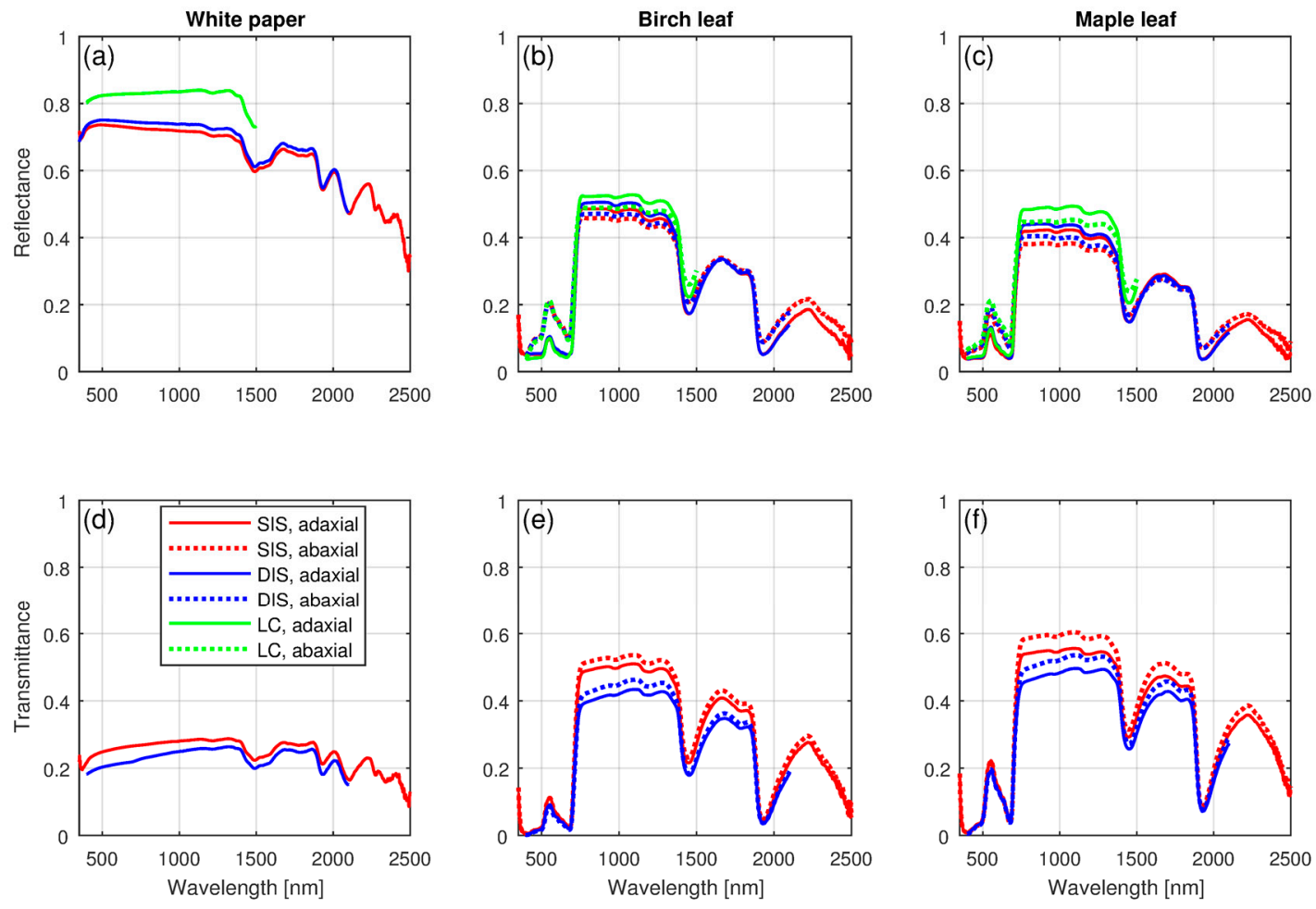

Figure 1. Mean reflectance and transmittance spectra of white paper, birch leaves, and maple leaves measured with different methods. SIS = single integrating sphere, DIS = double integrating sphere, LC = leaf clip. To avoid noisy regions due to low transmission of the fiber optic cables, spectra measured with DIS are presented only for 400-2100 nm, and those measured with LC for 400-1500 nm. Upper row (a-c) Reflectance; lower row (d-f) Transmittance.

\subsection{Within-Method Variability in the Measurements}

The standard deviations of the spectra at wavelengths between 400 and $2100 \mathrm{~nm}$ were less than 0.03 reflectance or transmittance units with all methods (Figure 2). There was no consistent difference in the standard deviations of measurements between DIS and SIS. In case of white paper, either SIS or DIS showed lower standard deviation, depending on whether reflectance or transmittance was measured. In birch, the standard deviations were almost equal, whereas in maple DIS tended to produce larger standard deviations than SIS. LC showed the largest standard deviations for all targets, except for adaxial side of maple leaves where standard deviation of DIS was slightly higher than LC (Figure 2c). Statistical tests confirmed the visual observations (Appendix B, Table A1). LC tended to differ from the other methods significantly, but no obvious difference was seen between DIS and SIS. When the integration time in DIS was reduced from $8.7 \mathrm{~s}$ to $0.544 \mathrm{~s}$, the standard deviation did not considerably change (Figure 3b,e). 

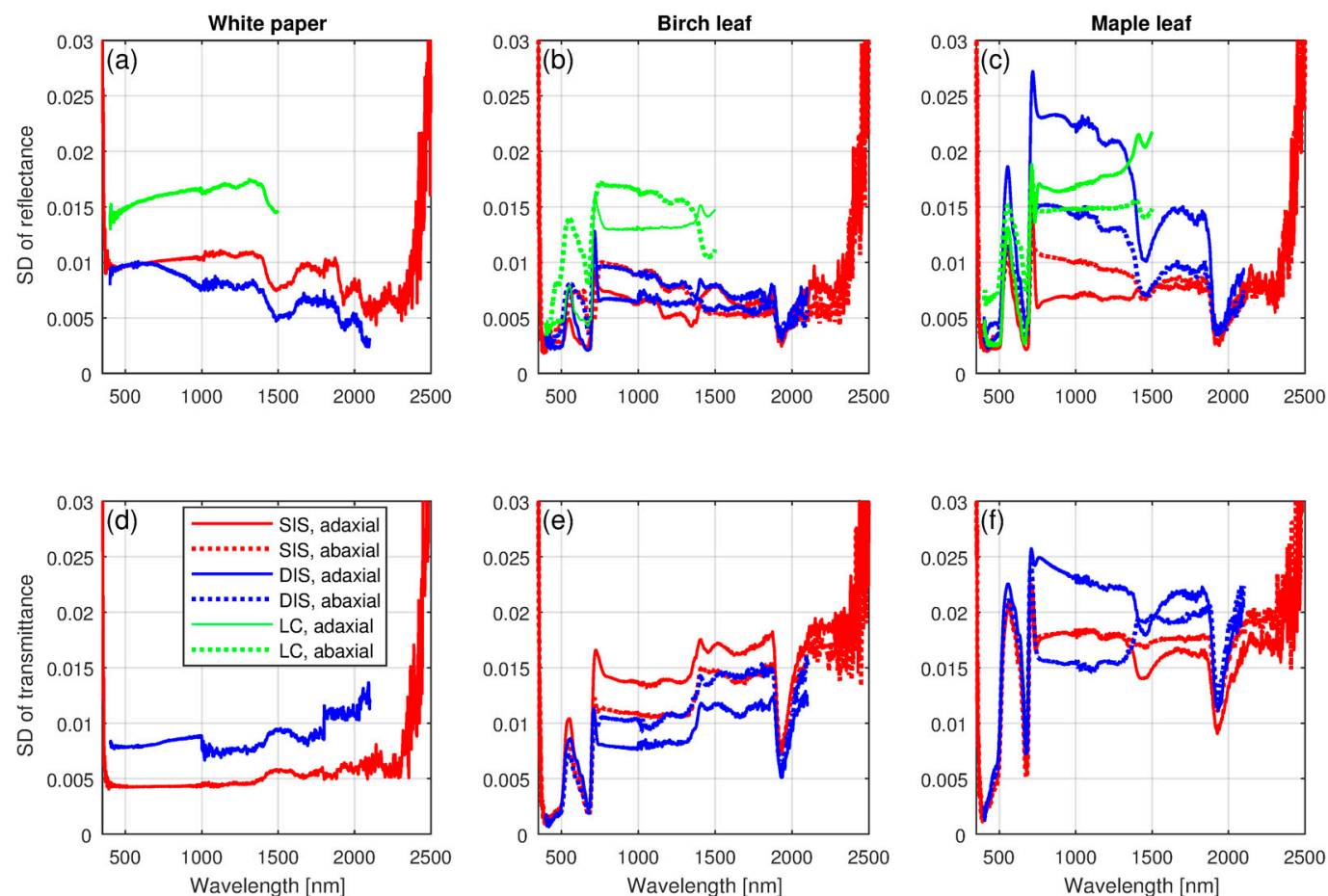

Figure 2. Standard deviations (SD) of reflectance and transmittance spectra of white paper, birch leaves, and maple leaves measured with different methods. SIS = single integrating sphere, DIS = double integrating sphere, LC = leaf clip. Upper row $(\mathbf{a}-\mathbf{c})$ Reflectance; lower row $(\mathbf{d}-\mathbf{f})$ Transmittance.
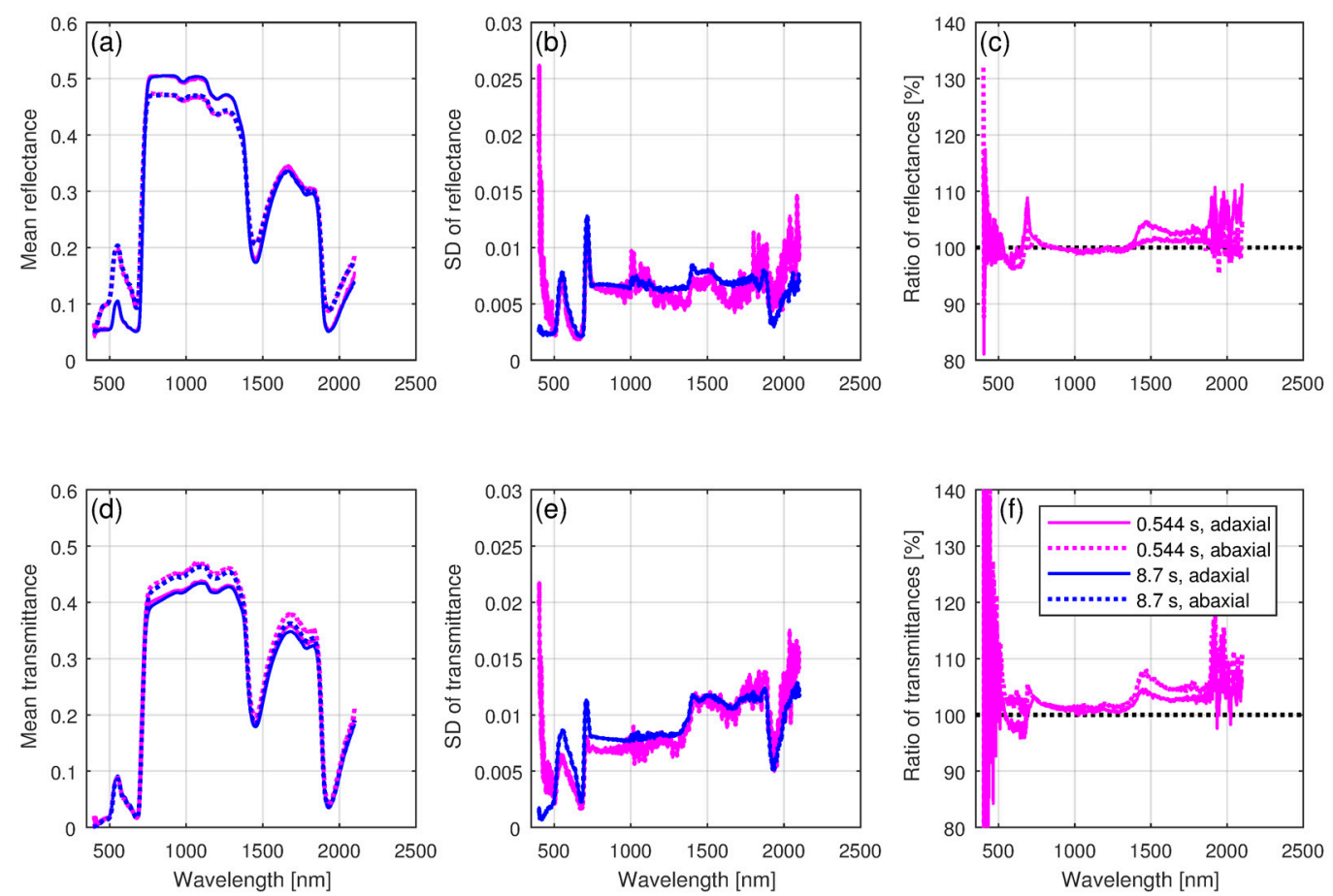

Figure 3. Comparison of birch leaf spectra measured with double integrating sphere, using either $8.7 \mathrm{~s}$ or $0.544 \mathrm{~s}$ integration time. (a) Mean reflectance; (b) Standard deviation of reflectance; (c) Ratio of mean reflectances (0.544 s to $8.7 \mathrm{~s}$ ); (d) Mean transmittance; (e) Standard deviation of transmittance; (f) Ratio of mean transmittances ( $0.544 \mathrm{~s}$ to $8.7 \mathrm{~s})$. 


\subsection{Systematic Differences between Methods}

\subsubsection{Mean Spectra}

Comparisons of measured mean spectra revealed clear differences between methods. The differences depended on the measured target and wavelength (Figures 4 and 5, Table 4) and were statistically significant for most of the targets and wavelengths (Appendix B, Table A2).
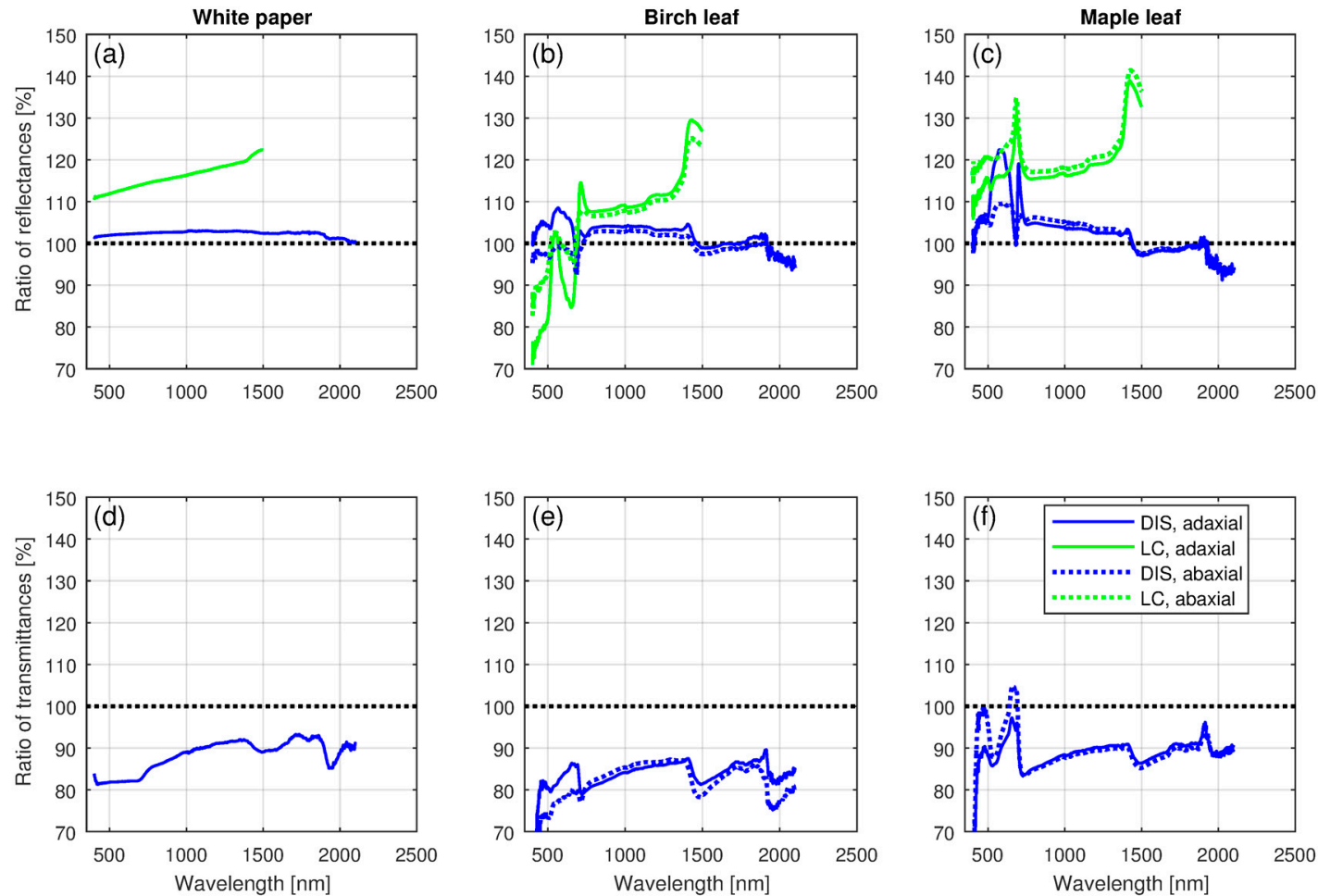

Figure 4. Ratios of mean spectra of white paper, birch leaves, and maple leaves measured with different methods. The $y$-axis denotes the ratio of double integrating sphere (DIS) or leaf clip (LC) to single integrating sphere (SIS). Upper row $(\mathbf{a}-\mathbf{c})$ Reflectance; lower row (d-f) Transmittance.
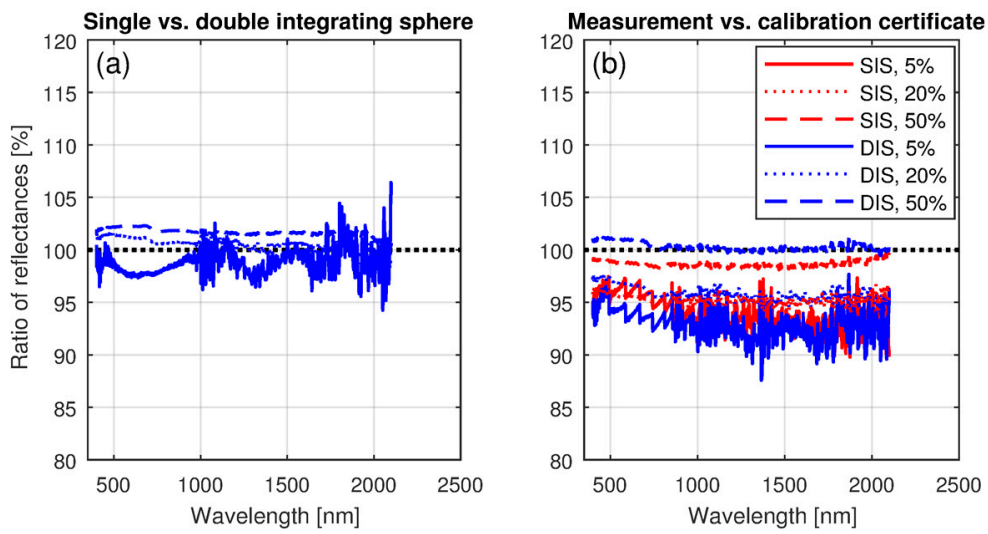

Figure 5. Ratios of mean reflectance spectra of gray-level standards (nominal reflectance values of $5 \%$, $20 \%$, and $50 \%$ ) measured with different methods. (a) Ratio of double integrating sphere (DIS) to single integrating sphere (SIS); (b) Ratios of double and single integrating spheres to spectra given in the calibration certificates of the standards. 
Table 4. Mean absolute difference (mean relative difference in parenthesis) of spectra measured with different methods at visible (VIS), near-infrared (NIR), shortwave-infrared (SWIR), and all wavelengths.

\begin{tabular}{|c|c|c|c|c|}
\hline Target & VIS (400-700 nm) & $\begin{array}{c}\text { NIR } \\
(700-1300 \mathrm{~nm})\end{array}$ & $\begin{array}{c}\text { SWIR } \\
\left(1300-2100 \mathrm{~nm}^{*}\right)\end{array}$ & $\begin{array}{l}\text { All Wavelengths } \\
(400-2100 \mathrm{~nm} *)\end{array}$ \\
\hline \multicolumn{5}{|c|}{ Double vs. single integrating sphere, reflectance } \\
\hline White paper & $0.015(2.0)$ & $0.020(2.8)$ & $0.014(2.2)$ & $0.016(2.4)$ \\
\hline Leaves & $0.004(5.0)$ & $0.016(3.8)$ & $-0.001(-1.2)$ & $0.006(1.7)$ \\
\hline Gray-level standards & $0.004(0.5)$ & $0.003(0.4)$ & $0.002(0.3)$ & $0.003(0.4)$ \\
\hline All targets & $0.005(2.9)$ & $0.011(2.4)$ & $0.002(-0.2)$ & $0.006(1.3)$ \\
\hline \multicolumn{5}{|c|}{ Double vs. single integrating sphere, transmittance } \\
\hline White paper & $-0.045(-18.1)$ & $-0.032(-11.6)$ & $-0.023(-9.5)$ & $-0.030(-11.7)$ \\
\hline Leaves & $-0.009(-16.3)$ & $-0.074(-14.2)$ & $-0.044(-13.6)$ & $-0.048(-14.3)$ \\
\hline All targets & $-0.016(-16.7)$ & $-0.065(-13.6)$ & $-0.040(-12.7)$ & $-0.045(-13.8)$ \\
\hline \multicolumn{5}{|c|}{ Leaf clip vs. single integrating sphere, reflectance } \\
\hline White paper & 0.091 (12.4) & 0.118 (16.4) & $0.135(20.4)$ & $0.113(16.1)$ \\
\hline Leaves & $0.006(5.6)$ & 0.054 (13.4) & $0.065(26.0)$ & 0.043 (13.5) \\
\hline All targets & $0.023(6.9)$ & $0.067(14.0)$ & 0.079 (24.9) & 0.057 (14.0) \\
\hline
\end{tabular}

* The upper wavelength limit is $1500 \mathrm{~nm}$ when comparing leaf clip vs. single integrating sphere.

The relative difference in reflectance between SIS and DIS was on average only $1 \%$ (i.e., DIS produced slightly higher reflectance), but ranged between $-9 \%$ and $22 \%$ (Figures 4 and 5 ). The largest differences were observed for maple leaves in the visible wavelengths, and the smallest for the white paper and gray-level standards (Figures 4 and 5, Table 4). When the reflectance values of gray-level standards measured by SIS and DIS were compared against the calibrated values of the standards, the differences were equal or even larger than the differences between these two methods (Figure $5 b$ ). LC produced clearly higher reflectance compared to the other methods in all targets, except for birch leaves in the visible wavelengths (Figure 4, Table 4). The average relative difference of LC to SIS was $14 \%$, ranging from $-29 \%$ to $41 \%$.

In the case of transmittance, large differences between SIS and DIS were observed. DIS produced notably lower transmittance values than SIS (Figure 4, Table 4). The relative difference was on average $-14 \%$, ranging between $-72 \%$ and $5 \%$. Reduction of the integration time from $8.7 \mathrm{~s}$ to $0.544 \mathrm{~s}$ with DIS did not influence the comparisons, except for that noise increased in wavelengths below $500 \mathrm{~nm}$ and above $1800 \mathrm{~nm}$ (Figure 3).

\subsubsection{Spectral Indices}

Spectral indices differed between methods, but also depending on whether they were calculated from reflectance and transmittance spectra, or from measurements of adaxial and abaxial sides of leaves (Figure 6). Figure 6 shows results only for birch, but the results for maple leaves were similar. Two groups of indices can be identified. Some of the indices (NDVI, CI, NDNI) did not depend on method, and the main sources of variability were leaf side and measured quantity (reflectance or transmittance). Some of the indices (SIPI, NDWI), however, were heavily influenced by the method (Figure 6, Appendix B, Table A3).

\subsection{Speed of Measurements}

Based on the measurement time evaluated for birch leaves, LC was clearly the fastest (1.3 min per leaf), and DIS the slowest $(15.0 \mathrm{~min})$, when using the integration times determined in the optimization. SIS fell in between these methods $(8.2 \mathrm{~min})$. With DIS, however, it was possible to reduce the measurement time to $2.2 \mathrm{~min}$, when the integration time was reduced from the optimum and set to $0.544 \mathrm{~s}$. 

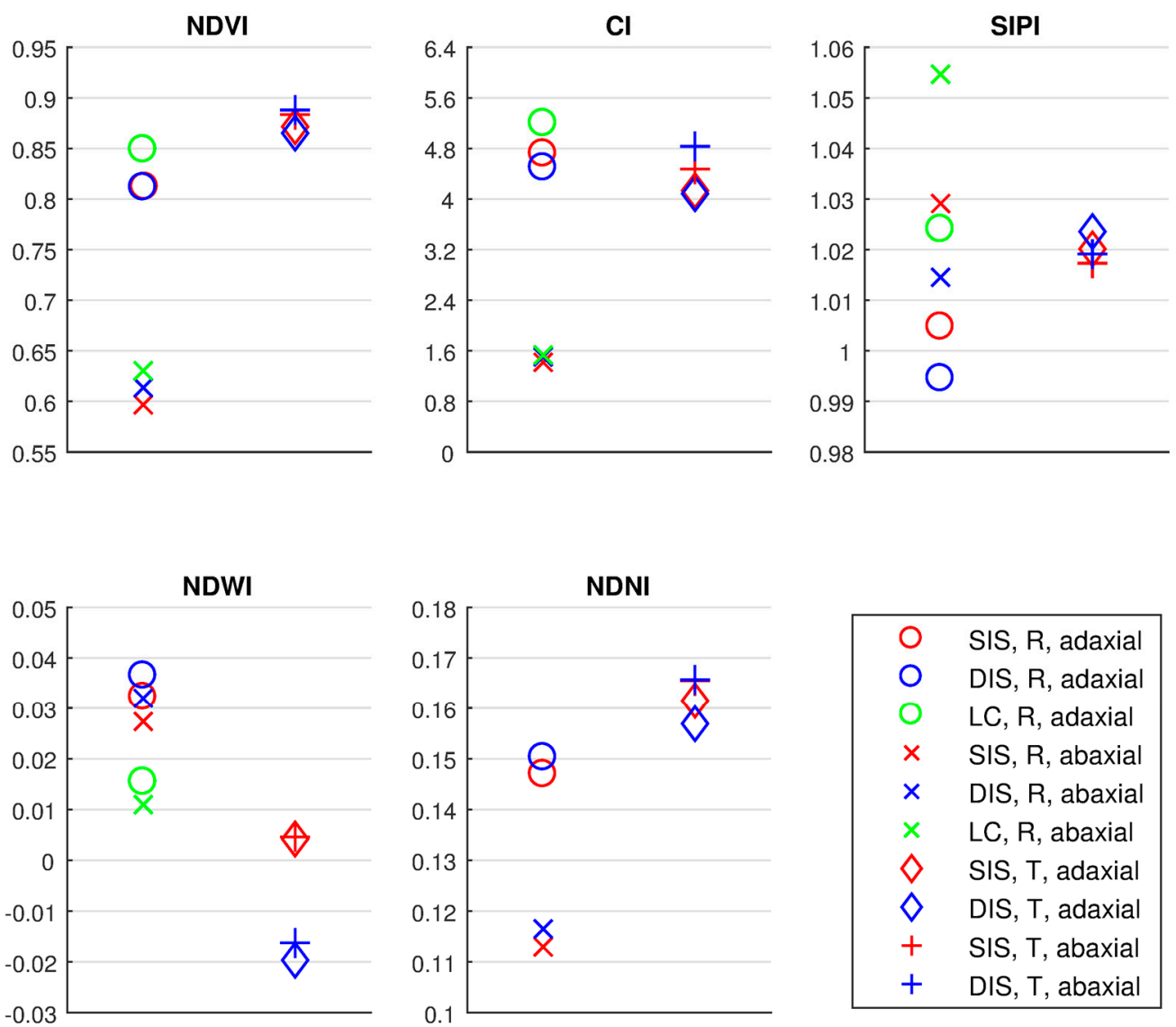

\begin{tabular}{|cc|}
\hline 0 & SIS, R, adaxial \\
0 & DIS, R, adaxial \\
0 & LC, R, adaxial \\
$\times$ & SIS, R, abaxial \\
$\times$ & DIS, R, abaxial \\
$\times$ & LC, R, abaxial \\
$\diamond$ & SIS, T, adaxial \\
$\diamond$ & DIS, T, adaxial \\
+ & SIS, T, abaxial \\
+ & DIS, T, abaxial \\
\hline
\end{tabular}

Figure 6. Dependence of spectral indices of birch leaves on measurement method, measured quantity (reflectance or transmittance), and leaf side. The values shown are mean values of indices calculated from the measured spectra (18 spectra per method). SIS = single integrating sphere, DIS = double integrating sphere, $\mathrm{LC}=$ leaf clip, $\mathrm{R}=$ reflectance, $\mathrm{T}=$ transmittance.

\section{Discussion}

\subsection{Within-Method Variability in the Measurements}

Previous studies have mainly focused on evaluating the accuracy in terms of systematic errors or differences between measurements methods [15-17]. Variability in repeated measurements is equally important, because it directly relates to the required number of measurements: The larger the variability in the measurements, the larger the number of measurements is needed to determine mean spectra reliably. Based on our results on standard deviation (Figure 2), it is possible to deduce the standard error of the mean for each method when the number of measurements is known. It can be seen that with any of the methods ten measurements is enough to obtain a standard error of mean less than 0.01 units. There were some differences between methods, discussed below, but generally it appears that all methods are suitable for precise spectral measurements, and using fast methods does not necessarily increase the variability in the measurements.

It is interesting that we observed no obvious differences in the standard deviations of measurements between SIS and DIS. DIS is notably faster in operation, yet the number of measurements can be maintained at about the same level. It should be noted that in order to operate DIS fast, the integration time had to be shortened from the optimum. This increased random noise at the low and high ends of the spectrum, but in most of the wavelengths the standard deviation did not increase (Figure 3). 
LC, representing contact probe types of measurements, showed the highest standard deviation among the methods. Due to the design of LC, the white reference had to be manually held in correct position during the measurement, which could have contributed to the results; the view and illumination angles in the white reference measurement easily varied between measurements. However, we observed similar differences between methods even when analyzing the raw sample measurement readings (data not shown). Assuming that the output power of the stabilized light source did not fluctuate, this indicates that the errors in white reference measurement are not the main reason for larger variability in measurements of LC compared to the other methods.

Intuitively, the standard deviation should depend on the size of the illuminated spot on the leaf, or the size of the sample port, because if larger area is sampled per measurement, there should be less variability between measurements due to spatial averaging. Contrary to our expectations, standard deviation of the measurements did not seem to depend clearly on the size of the illuminated spot on the leaf. LC illuminated the smallest area and had also the highest standard deviation. However, there was no clear difference between SIS and DIS, although SIS illuminates approximately a four times larger area. More research is needed on the variability of leaf optical properties at different scales: within leaves, between leaves of the same individual, and between plant individuals grown in similar or different conditions to help in planning optimal sampling designs for collection of spectral libraries of plants. To this end, the fast methods tested here are very useful, because they allow a large number of measurements to be performed in a relatively short time.

It should be noted that the standard deviation of measurements in DIS increased when measuring the maple leaves. Due to the shape and large size of the maple leaf and the design of DIS, the measurements with DIS had to be performed closer to the leaf tip than with the other methods. The leaf tip has more veins and possibly other irregularities in the leaf properties that may introduce extra variation in the measurements.

\subsection{Systematic Differences between Methods}

Based on our results, it is clear that there are systematic differences between the measurement methods. Direct implication of this is that particular care must be taken when comparing or combining measurements acquired with different methods. Systematic errors in leaf-level spectra can lead to respective over- or underestimation of canopy level reflectance when the leaf spectra are used as input in radiative transfer models. This problem could be somewhat mitigated by applying empirical or physically-based corrections to the measurements, or alternatively, adjusting the models to handle different types of input data. However, the differences between measurement methods depended on target (e.g., plant species). This indicates that no correction can fully remove the differences, unless information on target is included in the correction procedure. This could be very difficult in practice, since it would require measurement of target-specific empirical correction factors. The effects of target and wavelength are probably related to differences in spectral bi-directional reflectance distribution functions (BRDFs) of different targets. In the case of LC, the influence of BRDF is obvious since the measurement is performed in hotspot geometry, but also the integrating spheres may not integrate over the entire hemisphere, because there are walls around the sample port. To further complicate the matter, the optical properties of green leaves depend on incident irradiation and the duration of exposure to measurement light (e.g., $[9,10])$ which vary between methods. These changes are difficult to quantify and depend on the seasonally varying biochemical composition of the leaf as well as leaf's growing environment. Nevertheless, general differences between methods are evident and easily summarized: Small difference in reflectance but large difference in transmittance between SIS and DIS, and overestimation of reflectance by LC.

Although the differences in reflectance between SIS and DIS were statistically significant for most of the wavelengths, they can be considered relatively small. The maximum absolute difference did not exceed 0.027. In relative terms, large differences (up to $22 \%$ ) were observed for maple leaves in the visible wavelengths. However, the differences were not statistically significant for leaves in the visible 
region (Appendix B, Table A2). The differences of our measurements against the calibrated values of the reflectance standards were larger than differences between SIS and DIS, and the differences between SIS and DIS were also comparable to those observed by Lukeš et al. [16] between different integrating spheres. Thus, the differences in reflectance between SIS and DIS approached general level of accuracy observed in laboratory integrating spheres. However, it should be noted that the differences tended to be largest for leaves and smallest for gray-level standards (Table 4), indicating that there are BRDF effects.

The difference in transmittance measured by SIS and DIS was considerable. The average relative difference was $14 \%$, with DIS producing smaller values of transmittance. The most likely explanation for the difference is the attenuation of the light as it passes through the sample in the sample port of DIS. The sample port is surrounded by black walls (approximately $1 \mathrm{~mm}$ thick) that may absorb some of the diffusely scattered radiation from the sample or diffuse radiation entering the sample from either of the spheres. There may also be lateral losses that depend on the leaf thickness [15]. However, it is also possible that SIS overestimated transmittance. We calculated the ratio of the white reference signal of transmittance (empty port) measurement to the white reference signal of reflectance measurement, and noticed that white reference for transmittance was $92-96 \%$ of the white reference for reflectance. In theory (in an ideal sphere with identical sample illumination), they should be equal. The detected attenuation of white reference can indicate an overestimation of transmittance. Several explanations can be given for the differences in the white reference signals: (1) The light source was not perfectly collimated with some inevitable stray light. (2) The RTS-3ZC is designed to have a different distance between the sample and light source for reflectance and transmittance measurements causing differences in illumination irradiance. (3) There is potentially multiple scattering of radiation between the sample and the sphere lamp in RTS-3ZC [19], which may also result in transmittance overestimation.

We did not evaluate the measured transmittance values in absolute terms, because we did not have a calibrated transmittance standard available. An indication of the correctness of absorption values can be obtained by comparing to earlier measurements of absorption. Minimum NIR absorption was 0.07 for both birch and maple in DIS, and 0.01 for birch and 0.02 for maple in SIS. These values correspond to those measured earlier [4,15]. As discussed by Mõttus et al. [15], the minimum NIR absorption in DIS is somewhat larger than values reported for the same species or genera in previous studies and it is thus evident that DIS overestimates absorption. However, the values with SIS are close to zero, and some studies have even reported negative absorption [16], which indicates that slight overestimation of transmittance (and thus absorption) by SIS is also possible. We observed slightly negative minimum NIR absorption (-0.002) for SIS in case of white paper.

LC systematically overestimated leaf reflectance. It is known that leaf spectral BRDFs differ strongly from Lambertian [30] and that the measured reflectance factors therefore depend on view and illumination geometries. The reflectance factor of Spectralon is also dependent on view and illumination geometries [31,32]. Both Spectralon and leaves have increased reflectance in the hotspot direction [33-35], in which LC measures. It may be that compared to leaves, Spectralon reflects more diffusely and has a smaller peak in reflectance close to hotspot. This would explain the observed overestimation of leaf reflectance. Reflectance contributions originating from areas outside the leaf and multiple scattering from background (i.e., transmitted through the sample, reflected by background and transmitted again) explain only a small portion of the difference (see Section 2.2.3). Previous comparison between ASD contact probe and integrating spheres observed slightly smaller mean absolute differences than we did, indicating that factors such as the measurement geometry and design of the probe may influence the comparison [18]. Because leaf spectral BRDFs may vary between species [30], a contact probe is probably not the best choice for comparing spectral differences between species. However, it is well suitable for monitoring relative changes in reflectance and thus physiological status of plants in field conditions, which is where it is usually applied [8-10]. 
To illustrate the practical relevance of the differences, we computed spectral indices from the measured spectra (Figure 6). Indices particularly sensitive to between-method differences were those that are designed to track small changes in spectra (such as NDWI). Indices relying on high contrast between two wavelengths were not as sensitive (such as NDVI). In addition to showing between-method differences, we demonstrated that the spectral indices were highly dependent on whether they were calculated from leaf reflectance or transmittance spectra, or from adaxial or abaxial side of the leaf. All four quantities contribute to canopy spectral reflectance, and ignoring any of them may exert a large influence when the leaf optical properties are upscaled to canopy level. In fact, differences between methods, although significant, tended to be not as large as the differences between reflectance and transmittance, or the differences between leaf sides.

\subsection{Practical Applicability of the Methods}

Based on our results, considerable savings in time can be achieved by applying the fast methods (DIS and LC), compared to using SIS in which the attachment of the leaf sample is slow and the lamp has to be detached and reattached between reflectance and transmittance measurements. The design of the sphere and integration time (dependent on power of the light source and transmissivity of the optical fibers) obviously affect the measurement time. Thus, our results apply only to the specific instruments tested here. However, they give a good overview about the speed of measurements obtainable with different types of methods. It should also be noted that the measurement time depends somewhat on the characteristics of the target. For example, measuring birch leaves was slower than measuring maple leaves with SIS, because attaching a birch leaf to SIS was more difficult than attaching a maple leaf due to the small size of the leaf in comparison to the sample holder.

There are also numerous other criteria that influence which of the methods is best suitable for a specific application. Firstly, ease of operation affects not only time but also how error-prone the measurements are. Based on our experience, attaching a leaf to the sample port of SIS requires particular care. It was difficult, particularly with small leaves, to avoid undulations in the leaf surface. The surface should be as smooth as possible to avoid errors in the measurement. The same problem was also recognized by Lukeš et al. [16] who noted that particularly the transmittance measurement is prone to errors. This may, however, be a specific property of RTS-3ZC, not all single integrating spheres. When using DIS the leaf is easy to attach and the measurements less error-prone. The only difficulty was that the instrument operator cannot see the illuminated spot on the leaf, and therefore it is sometimes difficult to avoid measuring leaf veins or other irregularities. This may cause additional variation in the measurements. LC is the least error-prone what comes to attachment of the leaf. It is easy to see which area is measured, and the leaf is always firmly attached in the clip. An obvious source of error, however, comes from the difficulty of measuring the white reference, as described in Section 4.1. This problem could probably be overcome by using a custom-made holder for the white reference.

With DIS and LC the measurements can only be performed from within a few centimeters from the edge of the leaf. Central areas of large leaves cannot be measured unless the leaf is cut, which in turn may induce physiological changes. SIS was more flexible to accommodate small and large leaves.

Ruggedness and portability are important if the methods are applied in field conditions. Both DIS and LC are mechanically durable with very few loose parts. In this sense they are clearly better than SIS when performing measurements in the field or in remote locations. In addition, they are easy to keep clean. In SIS, dust, litter, and other particles easily end up inside the sphere. What comes to portability, LC and DIS are small enough for one person to carry in the field, at least if they are connected to a spectrometer with an integrated light source as provided by the manufacturers. If operated together with an external light source as we did, the amount of equipment to carry is somewhat larger. SIS needs to be set up on a tripod or other stable surface, and it is also heavy to carry for long distances in e.g., forests. 
An important thing to consider if measuring in field conditions is the movement of the fiber optic cables. In our measurements we did not excessively move the cables, but small movements were allowed with DIS and LC, when the leaf was attached to the measurement system. By taking repeated spectrometer readings of stable targets (empty DIS or white paper attached to LC) we verified that the additional variability introduced by not fixing the position of the cables was in the order of $1 \%$ or less (coefficient of variation) throughout all wavelengths. Thus, it did not considerably influence the results. However, moving the two meter long cable used with DIS for the whole of its length introduced even up to $10 \%$ variation in the measurement. However, the short bifurcated cable in LC was not as prone to errors.

\subsection{Limitations and Future Directions}

Our aim was to compare commercial off-the-shelf methods in a typical experimental setup in which the user needs to determine mean spectra of a given target accurately (e.g., leaves in the upper part of tree canopy in a certain site). The choice of our experimental setup had two consequences. First, the reported within-method variabilities (standard deviations) contain compound effects of the precision of the measurement system itself and sampling variance that occurs when measuring a spatially varying target. Further research should therefore be aimed at analyzing reasons for within-method variability in the measurements even in more detail, e.g., relations between sampling variance and illuminated spot size, variation in optical properties within and between leaves, and measurement precision of the methods when taking repeated measurements of the same spot on a same sample. Second, the illumination conditions (irradiance, duration of exposure) were not normalized between methods, which may have influenced the optical properties of plant leaves, particularly in certain wavelengths in the visible spectral region. However, we avoided analyzing spectral indices known to be particularly sensitive to illumination conditions [36].

More extensive studies, containing e.g., larger variation of species, could elucidate species dependencies further, i.e., to what extent it is possible to remove between-method differences in spectra by applying general (species-independent) correction factors. Finally, as the accuracy requirements are highly application-dependent, targeted studies which focus on particular applications are needed to further demonstrate practical significance of the differences. These studies could also utilize radiative transfer models to demonstrate the effects of errors in leaf reflectance and transmittance measurements on modeled canopy reflectance.

\section{Conclusions}

This study reported for the first time a comparison of a small double integrating sphere and a leaf clip against a single integrating sphere in leaf optical properties measurements. Compared to a single integrating sphere, the double integrating sphere and leaf clip were considerably faster and easier to operate, but the within-method variability in the measurements was similar or only slightly increased. However, there were systematic differences in the measured spectra. Based on the results, particular care must be taken when comparing or combining spectra measured with different methods. Because the differences seem to be dependent on wavelength and species, it is difficult to develop correction procedures for homogenizing spectral databases collected with different methods. However, for monitoring relative changes in spectra over time, any of the tested methods is suitable.

Acknowledgments: This work was supported by the Academy of Finland (grants 286390 and 266152). Antti Pietilä (University of Helsinki, Department of Physics) kindly provided the gray-level standards. Thanks also to Anita Pirhonen (Aalto University, School of Chemical Engineering) for help in finding a suitable white paper for measurements.

Author Contributions: A.H., M.R. and M.M. conceived and designed the experiments; P.F. and A.H. performed the experiments; P.F. processed the data; A.H. and P.F. analyzed the data; A.H. prepared the first draft of the manuscript. All co-authors participated in discussing the results and writing the manuscript.

Conflicts of Interest: The authors declare no conflict of interest. 


\section{Appendix A}

When measuring in comparison mode, i.e., when the average reflectance of the sphere inner wall (including sphere ports) is constant, transmittance of a sample is simply

$$
T=\frac{I_{s}}{I_{\text {ref, theor }}},
$$

where $I_{S}$ is the spectrometer reading obtained from the sample, and $I_{\text {ref, theor }}$ is the spectrometer reading obtained when measuring an ideal diffuse transmittance standard $(T=1)$. Because there exist no such standard, $I_{\text {ref,theor }}$ must be estimated from reflectance measurement of a (near-perfect) reference target, such as a $99 \%$ Spectralon

$$
I_{\text {ref }}=\left(I_{\text {ref,theor }}-I_{d}\right) \times R_{r e f}+I_{d},
$$

where $I_{\text {ref }}$ is the spectrometer reading obtained from the reference target, $I_{d}$ is the stray light, and $R_{r e f}$ is the reflectance factor of the reference target. Note that stray light is present in the reference measurement (Equation (A2)), but not in the measurement of the sample $\left(I_{s}\right)$, because the sample prevents any stray light from entering the sphere. From Equation (A2) we calculate $I_{\text {ref, theor }}$ as

$$
I_{r e f, t h e o r}=\left[I_{r e f}-I_{d} \times\left(1-R_{r e f}\right)\right] \times \frac{1}{R_{r e f}}
$$

Substituting Equation (A3) into Equation (A1) we obtain the equation for transmittance (same as Equation (2) in the main text):

$$
T=\frac{I_{s}}{I_{r e f}-I_{d} \times\left(1-R_{r e f}\right)} \times R_{r e f}
$$

The term $I_{d} \times\left(1-R_{r e f}\right)$ is negligible, and can be ignored, but we kept it for sake of thoroughness.

\section{Appendix B}

Results on statistical tests comparing the methods (Tables A1-A3). Table A1: Levene's test for equality of variances. Table A2: Welch's $t$-test for equality of mean spectra. Table A3: Welch's $t$-test for equality of mean spectral indices.

Table A1. Mean $p$-values in Levene's test comparing homogeneity of variances between measurement methods. The value for each wavelength region (VIS, NIR, SWIR) is the mean of individual $p$-values of all $1 \mathrm{~nm}$ bands belonging to the region. Statistically significant regions $(p<0.05)$ are highlighted. $\mathrm{R}=$ reflectance, $\mathrm{T}=$ transmittance, $\mathrm{AD}=$ adaxial side, $\mathrm{AB}=$ abaxial side.

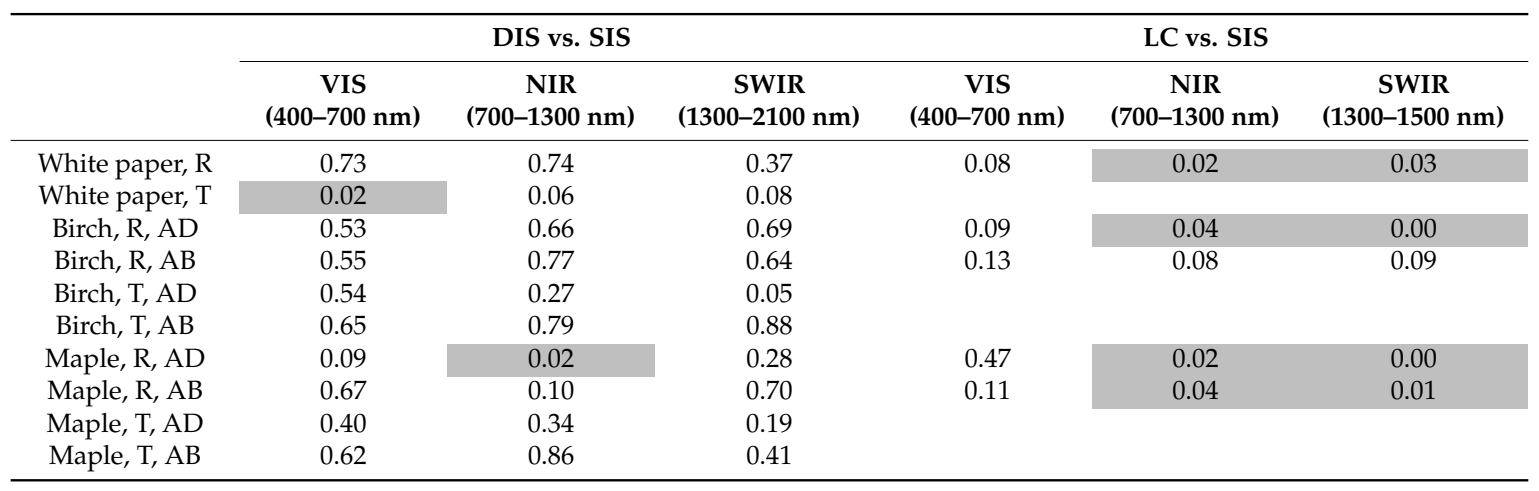


Table A2. Mean $p$-values in Welch's $t$-test comparing differences in mean spectra between measurement methods. The value for each wavelength region (VIS, NIR, SWIR) is the mean of individual $p$-values of all $1 \mathrm{~nm}$ bands belonging to the region. Statistically significant regions $(p<0.05)$ are highlighted. $\mathrm{R}=$ reflectance, $\mathrm{T}=$ transmittance, $\mathrm{AD}=$ adaxial side, $\mathrm{AB}=$ abaxial side.

\begin{tabular}{|c|c|c|c|c|c|c|}
\hline & \multicolumn{3}{|c|}{ DIS vs. SIS } & \multicolumn{3}{|c|}{ LC vs. SIS } \\
\hline & $\begin{array}{c}\text { VIS (400-700 } \\
\mathrm{nm})\end{array}$ & $\begin{array}{c}\text { NIR } \\
(700-1300 \mathrm{~nm})\end{array}$ & $\begin{array}{c}\text { SWIR } \\
(1300-2100 \mathrm{~nm})\end{array}$ & $\begin{array}{c}\text { VIS (400-700 } \\
\mathrm{nm})\end{array}$ & $\begin{array}{c}\text { NIR } \\
(700-1300 \mathrm{~nm})\end{array}$ & $\begin{array}{c}\text { SWIR } \\
(1300-1500 \mathrm{~nm})\end{array}$ \\
\hline White paper, $\mathrm{T}$ & 0.00 & 0.00 & 0.00 & & & \\
\hline Birch, R, AD & 0.07 & 0.01 & 0.34 & 0.12 & 0.00 & 0.00 \\
\hline Birch, R, AB & 0.20 & 0.03 & 0.14 & 0.24 & 0.00 & 0.00 \\
\hline Maple, R, AD & 0.11 & 0.02 & 0.26 & 0.00 & 0.00 & 0.00 \\
\hline Maple, R, AB & 0.07 & 0.00 & 0.21 & 0.00 & 0.00 & 0.00 \\
\hline Maple, T, AD & 0.11 & 0.00 & 0.01 & & & \\
\hline Maple, T, AB & 0.37 & 0.00 & 0.01 & & & \\
\hline
\end{tabular}

Table A3. Statistical differences in spectral indices calculated with different methods. The values shown are $p$-values in a $t$-test comparing double integrating sphere (DIS) or leaf clip (LC) to single integrating sphere. Statistically significant values $(p<0.05)$ are highlighted. $\mathrm{R}=$ reflectance, $\mathrm{T}=$ transmittance, $\mathrm{AD}=$ adaxial side, $\mathrm{AB}=$ abaxial side.

\begin{tabular}{|c|c|c|c|c|c|c|}
\hline Spectrum & DIS & LC & DIS & LC & DIS & $\mathrm{LC}$ \\
\hline & \multicolumn{2}{|c|}{ NDVI } & \multicolumn{2}{|c|}{ CI } & \multicolumn{2}{|c|}{ SIPI } \\
\hline Birch, R, AD & 0.823 & 0.000 & 0.085 & 0.001 & 0.000 & 0.000 \\
\hline Birch, R, AB & 0.006 & 0.000 & 0.008 & 0.002 & 0.000 & 0.000 \\
\hline Birch, T, AD & 0.166 & - & 0.793 & - & 0.001 & - \\
\hline Birch, $T, A B$ & 0.168 & - & 0.015 & - & 0.005 & - \\
\hline Maple, R, AD & 0.119 & 0.145 & 0.005 & 0.977 & 0.000 & 0.000 \\
\hline Maple, R, AB & 0.061 & 0.003 & 0.213 & 0.104 & 0.000 & 0.000 \\
\hline Maple, T, AD & 0.039 & - & 0.499 & - & 0.004 & - \\
\hline \multirow[t]{2}{*}{ Maple, T, AB } & 0.001 & - & 0.104 & - & 0.000 & - \\
\hline & \multicolumn{2}{|c|}{ NDWI } & \multicolumn{2}{|c|}{ NDNI } & & \\
\hline Birch, R, AD & 0.000 & 0.000 & 0.047 & 0.000 & & \\
\hline Birch, R, AB & 0.000 & 0.000 & 0.006 & 0.000 & & \\
\hline Birch, T, AD & 0.000 & - & 0.007 & - & & \\
\hline Birch, T, AB & 0.000 & - & 0.865 & - & & \\
\hline Maple, R, AD & 0.000 & 0.000 & 0.200 & 0.000 & & \\
\hline Maple, R, AB & 0.000 & 0.000 & 0.054 & 0.000 & & \\
\hline Maple, T, AD & 0.000 & - & 0.923 & - & & \\
\hline Maple, T, AB & 0.000 & - & 0.106 & - & & \\
\hline
\end{tabular}

\section{References}

1. Gates, D.M.; Keegan, H.J.; Schleter, J.C.; Weidner, V.R. Spectral properties of plants. Appl. Opt. 1965, 4, 11-20. [CrossRef]

2. Hosgood, B.; Jacquemoud, S.; Andreoli, G.; Verdebout, J.; Pedrini, A.; Schmuck, G. Leaf Optical Properties Experiment 93 (LOPEX93); Revised Report EUR16095EN (JRC); European Commission: Brussels, Belgium, 1995.

3. Middleton, E.M.; Sullivan, J.H.; Bovard, B.D.; Deluca, A.J.; Chan, S.S.; Albert, P. Seasonal variability in foliar characteristics and physiology for boreal forest species at the five Saskatchewan tower sites during the 1994 Boreal Ecosystem-Atmosphere Study. J. Geophys. Res. 1997, 102, 28831-28844. [CrossRef]

4. Lukeš, P.; Stenberg, P.; Rautiainen, M.; Mõttus, M.; Vanhatalo, K. Optical properties of leaves and needles for boreal tree species in Europe. Remote Sens. Lett. 2013, 4, 667-676. [CrossRef]

5. Mõttus, M.; Sulev, M.; Hallik, L. Seasonal course of the spectral properties of alder and birch leaves. IEEE J. Sel. Top. Appl. 2014, 7, 2496-2505. [CrossRef] 
6. Carr, K.F. Integrating sphere theory and applications. Part II: Integrating sphere applications. Surf. Coat. Int. 1997, 80, 485-490. [CrossRef]

7. Richardson, A.D.; Duigan, S.P.; Berlyn, G.P. An evaluation of noninvasive methods to estimate foliar chlorophyll content. New Phytol. 2002, 153, 185-194. [CrossRef]

8. Hernández-Clemente, R.; Navarro-Cerrillo, R.M.; Zarco-Tejada, P.J. Carotenoid content estimation in a heterogeneous conifer forest using narrow-band indices and PROSPECT+DART simulations. Remote Sens. Environ. 2012, 127, 298-315. [CrossRef]

9. Gamon, J.A.; Bond, B. Effects of irradiance and photosynthetic downregulation on the photochemical reflectance index in Douglas-fir and ponderosa pine. Remote Sens. Environ. 2013, 135, 141-149. [CrossRef]

10. Mõttus, M.; Hernández-Clemente, R.; Perheentupa, V.; Markiet, V. In situ measurement of Scots pine needle PRI. Plant Methods 2017, 13, 35. [CrossRef] [PubMed]

11. Miller, J.R.; Steven, M.D.; Demetriades-Shah, T.H. Reflection of layered bean leaves over different soil backgrounds: Measured and simulated spectra. Int. J. Remote Sens. 1992, 13, 3273-3286. [CrossRef]

12. OceanOptics Inc. SpectroClip Probe, Installation and Operation Manual; Document Number 000-specc-110-02-201203; OceanOptics Inc.: Dunedin, FL, USA, 2012.

13. Pickering, J.W.; Moes, C.J.M.; Sterenborg, H.J.C.M.; Prahl, S.A.; van Gemert, M.J. C. Two integrating spheres with an intervening scattering sample. J. Opt. Soc. Am. 1992, A9, 621-631. [CrossRef]

14. Pickering, J.W.; Prahl, S.; van Wieringen, N.; Beek, J.F.; Sterenborg, H.J.; van Gemert, M.J. Double-integrating-sphere system for measuring the optical properties of tissue. Appl. Opt. 1993, 32, 399-410. [CrossRef] [PubMed]

15. Mõttus, M.; Hovi, A.; Rautiainen, M. Theoretical algorithm and application of a double-integrating sphere system for measuring leaf transmittance and reflectance spectra. Appl. Opt. 2017, 56, 563-571. [CrossRef] [PubMed]

16. Lukeš, P.; Homolová, L.; Navrátil, M.; Hanuš, J. Assessing the consistency of optical properties measured in four integrating spheres. Int. J. Remote Sens. 2017, 38, 3817-3830. [CrossRef]

17. Olascoaga, B.; Mac Arthur, A.; Atherton, J.; Porcar-Castell, A. A comparison of methods to estimate photosynthetic light absorption in leaves with contrasting morphology. Tree Physiol. 2016, 36, 368-379. [CrossRef] [PubMed]

18. Potůčková, M.; Červená, L.; Kupková, L.; Lhotáková, Z.; Lukeš, P.; Hanuš, J.; Novotný, J.; Albrechtová, J. Comparison of reflectance measurements acquired with a contact probe and an integration sphere: Implications for the spectral properties of vegetation at a leaf level. Sensors 2016, 16, 1801. [CrossRef]

19. ASD Inc. Integrating Sphere User Manual; ASD Document, 600660 Rev. B; ASD Inc.: Longmont, CO, USA, 2008.

20. Daughtry, C.S.T.; Biehl, L.L.; Ranson, K.J. A new technique to measure the spectral properties of conifer needles. Remote Sens. Environ. 1989, 27, 81-91. [CrossRef]

21. Mesarch, M.A.; Walter-Shea, E.A.; Asner, G.P.; Middleton, E.M.; Chan, S.S. A revised measurement methodology for conifer needles spectral optical properties: Evaluating the influence of gaps between elements. Remote Sens. Environ. 1999, 68, 177-192. [CrossRef]

22. Yanez-Rausell, L.; Malenovsky, Z.; Clevers, J.G.P.W.; Schaepman, M.E. Minimizing Measurement Uncertainties of Coniferous Needle-Leaf Optical Properties, Part II: Experimental set-up and error analysis. IEEE J. Sel. Top. Appl. Earth Obs. Remote Sens. 2014, 7, 1-15. [CrossRef]

23. R Core Team. R: A Language and Environment for Statistical Computing; R Foundation for Statistical Computing: Vienna, Austria, 2017.

24. Rouse, J.W., Jr.; Haas, R.H.; Schell, J.A.; Deering, D.W.; Harian, J.C. Monitoring vegetation systems in the great plains with ERTS. In Third Earth Resources Technology Satellite-1 Symposium, Technical Presentations, Section A, vol. I; Freden, S.C., Mercanti, E.P., Becker, M., Eds.; National Aeronautics and Space Administration: Washington, DC, USA, 1973; NASA SP-351; pp. 309-317.

25. Gitelson, A.A.; Gritz, Y.; Merzlyak, M.N. Relationships between leaf chlorophyll content and spectral reflectance and algorithms for non-destructive chlorophyll assessment in higher plant leaves. J. Plant Physiol. 2003, 160, 271-282. [CrossRef] [PubMed]

26. Peñuelas, J.; Baret, F.; Filella, I. Semi-empirical indices to assess carotenoids/chlorophyll a ratio from leaf spectral reflectance. Photosynthetica 1995, 31, 221-230.

27. Gao, B.C. NDWI-A normalized difference water index for remote sensing of vegetation liquid water from space. Remote Sens. Environ. 1996, 58, 257-266. [CrossRef] 
28. Serrano, L.; Penuelas, J.; Ustin, S.L. Remote sensing of nitrogen and lignin in Mediterranean vegetation from AVIRIS data: Decomposing biochemical from structural signals. Remote Sens. Environ. 2002, 81, 355-364. [CrossRef]

29. Barsi, J.A.; Lee, K.; Kvaran, G.; Markham, B.L.; Pedelty, J.A. The Spectral Response of the Landsat-8 Operational Land Imager. Remote Sens. 2014, 6, 10232-10251. [CrossRef]

30. Bousquet, L.; Lachérade, S.; Jacquemoud, S.; Moya, I. Leaf BRDF measurements and model for specular and diffuse components differentiation. Remote Sens. Environ. 2005, 98, 201-211. [CrossRef]

31. Jackson, R.D.; Clarke, T.R.; Moran, S.M. Bidirectional calibration results for 11 Spectralon and $16 \mathrm{BaSO}_{4}$ reference reflectance panels. Remote Sens. Environ. 1992, 40, 231-239. [CrossRef]

32. Voss, K.J.; Zhang, H. Bidirectional reflectance of dry and submerged Spectralon plaque. Appl. Opt. 2006, 45, 7924-7927. [CrossRef] [PubMed]

33. Kaasalainen, S.; Rautiainen, M. Backscattering measurements of individual Scots pine needles. Appl. Opt. 2007, 46, 4916-4922. [CrossRef] [PubMed]

34. Comar, A.; Baret, F.; Viénot, F.; Yan, L.; de Solan, B. Wheat leaf bidirectional reflectance measurements: Description and quantification of the volume, specular and hot-spot scattering features. Remote Sens. Environ. 2012, 121, 26-35. [CrossRef]

35. Rabal, A.M.; Ferrero, A.; Campos, J.; Pons, A.; Hernanz, M.L. Bidirectional reflectance distribution function of diffuse reflectance standards around the retro-reflection direction. Metrologia 2014, 51, 148-153. [CrossRef]

36. Peñuelas, J.; Filella, I.; Gamon, J.A. Assessment of photosynthetic radiation-use efficiency with spectral reflectance. New Phytol. 1995, 131, 291-296. [CrossRef]

(C) 2017 by the authors. Licensee MDPI, Basel, Switzerland. This article is an open access article distributed under the terms and conditions of the Creative Commons Attribution (CC BY) license (http:// creativecommons.org/licenses/by/4.0/). 